\title{
A normative analysis to determine the goals of ethics education through utilizing three approaches: rational moral education, ethical acculturation, and learning throughout life
}

\author{
Ercan Avci $^{1}$ (D)
}

Published online: 16 February 2017

(C) Springer International Publishing AG 2017

\begin{abstract}
Ethics education is an emerging concept at the intersection of ethics and education, and this article aims to define the goals of ethics education in order to specify the general structure of teaching ethics in healthcare. Additionally, providing the opportunity to map the next stages of ethics education, such as what to teach and how to teach, is another purpose of the suggested normative framework. Kohlberg's cognitive-developmental approach, Handelsman et al.'s ethical acculturation model, and the Delors Report's learning throughout life concept are utilized to determine the notion of teaching ethics and its objectives. Through the integration of these three approaches and the adaptation of the Delors Report's pillars, the goals of ethics education are described as: (1) increasing ethical knowledge; (2) improving ethical skills to strengthen ethical sensitivity, awareness, and judgement; (3) developing ethical behavior; and (4) promoting cultural competence. These goals indicate that ethics education is an ongoing process transcending to teach or learn certain ethical codes, norms, and principles. Exploring and recognizing individuals' abilities, personal values, and cultural backgrounds are also essential requirements of teaching ethics. Furthermore, this perspective demands administrating existing ethical challenges, differences, and conflicts in healthcare through augmenting cultural competence rather than imposing and/or assimilating policies.
\end{abstract}

Keywords Goals of ethics education - Ethics - Education - Ethical acculturation · Pillars of the Delors report

Ercan Avci

avciercan@yahoo.com; avcie@duq.edu

1 Center for Healthcare Ethics-Duquesne University, 300 Fisher Hall, 600 Forbes Avenue,

Pittsburgh, PA 15282, USA 


\section{Introduction}

Ethics education is an essential concept associated with almost all academic fields including healthcare. Many research studies demonstrate that ethics education improves ethical sensitivity, knowledge, awareness, and judgement. However, there is not a consensus on the goal, scope, and method of teaching ethics (Avci 2016; Boon 2011; Canary et al. 2014; Cannaert et al. 2014; Lau 2010). Furthermore, quality in ethics education and the measurement of quality are some other issues which require more academic studies to settle a general agreement. A solid theoretical foundation of ethics education cannot be established without specifying its objectives. Therefore, to decide what the goal/goals of ethics education is/are would be the first and foremost step to create a concrete background to determine the scope and method as well as quality standards and indicators of ethics education. In this sense, the aim of this paper is to underscore the importance of ethics education in healthcare and draw a general framework regarding the goals of ethics education from a normative perspective.

\section{Ethics and education}

The term ethics education is a phrase originating from two words: ethics and education. Though ethics education refers to the teaching of ethics, examining the components of the phrase as ethics and education would make the conceptual structure more understandable by clarifying the meaning and components of these words. However, both ethics and education are broad terms including many theoretical elements, views, and insights. In this paper, the terms ethics and education will be succinctly studied to explain what they imply. For this reason, the historical and philosophical emergence and background of these terms are beyond the scope of this paper.

\section{Ethics and morality}

During growth, children start learning societal values from their parents, society, and social, educational, and religious institutions. Individuals and communities usually strive to pass on their own values to the new members of the society or want to raise them with certain values in order to contribute to their moral development. However, this mostly happens through a long and slow continuum. For instance, when a parent realizes the child hides something from her/him due to the fear of any consequences of telling the truth which the child envisions, the parent encourages her/him to tell the truth without worrying about the results of the disclosure. Nonetheless, urging children to tell the truth may not be sufficient because they desire to be persuaded by convincing explanations to clarify why they should tell the truth or not. For this reason, analyzing the moral aspect of conduct is significantly important to determine what to do or not to do and why to do or not to do (LaFollette 2014).

Many philosophers and authors have held discussions regarding the relationship between morality and ethics, some of whom acknowledge these terms as synonymous, while some others reveal certain distinctions between these terms. Even though it is believed that morality differs from ethics at some points, such as dissimilarities between 
their origins and scopes, to some extent, morality and ethics may be considered interchangeable (Bendik-Keymer 2013). However, because of widespread use of these words (ethics, ethical, morality, moral, morally), in the present paper, morality will briefly be compared with ethics and the leading features of these two terms will be highlighted to elucidate the conceptual framework without plunging into a deep philosophical debate.

The Cambridge Dictionary (http://dictionary.cambridge.org 2016) delineates morality as "a personal or social set of standards for good or bad behavior and character, or the quality of being right and honest," and designates ethics as "the study of what is morally right and wrong, or a set of beliefs about what is morally right and wrong." From this perspective, morality exhibits some standards to decide which personal or social attitudes and behaviors are good or bad. In other words, morality contains a guideline gauging the acceptability of personal and social conduct. The dictionary describes ethics as utilizing morality and regards it as a study which determines what is morally right or wrong. The lexical definition of these terms indicates that morality refers to a set of standards demonstrating what is good and bad, whereas ethics shows what is morally right and wrong. However, these definitions may not be sufficient to explain the rightness and wrongness of attitudes and behaviors and should be expanded and more fully explored to understand the complex distinctions between morality and ethics.

According to Jeremy Bendik-Keymer (2013), ethics is a term older and broader than morality; the former goes back to Ancient Greek, whereas the latter comes from a Judeo-Christian background. In accordance with Bendik-Keymer's approach (2013), ethics focuses on the question: "how should I live," while morality looks for the answers of "how I must relate" and "how I am to relate to others as a human being" (p. 11-13). Bernard Gert (2005) describes morality as "an informal public system applying to all rational persons, governing behavior that affects others, and includes what are commonly known as the moral rules, ideals, and virtues and has the lessening of evil or harm as its goal" (p. 14). Karen L. Rich (2016) accepts ethics "[a]s a philosophical discipline of study" and defines it as "a systematic approach to understanding, analyzing, and distinguishing matters of right and wrong, good and bad, and admirable and deplorable as they relate to the well-being of and the relationship among sentient beings" (p. 4). From all these explanations, it can be stated that even though there is a close connection between ethics and morality due to their common concentration on deciding what is right and wrong, some differences may be noted.

Morality is a combination of rules, values and standards shaping the rightness and wrongness of individual and social conduct. However, the universality of morality is a controversial issue. Cultural and religious factors influence morality and its components. In this sense, each culture and religion carries some unique moral rules, values, and standards (Schowengerdt 2014). Although some authors, like Bernard Gert (2005), claim the possibility of presenting a common morality, it is believed that an attempt to generate a universal morality is not feasible as well as not needed. Of course, a common definition of morality may be established. However, in the case of focusing on moral rules and values building moral systems, certain differences are likely to be encountered (Schowengerdt 2014). There can be many moral norms accepted by almost all moral systems, such as not lying, not harming, and helping others, but this situation does not prove there is an exact similarity among all moral systems. As Gert (2005) 
emphasizes, mitigating evil and harm may be regarded as a goal of morality. Nonetheless, dissimilarities in the description of evil and harm might naturally bring about distinctions among different moral systems.

On the other hand, ethics is the study of philosophy analyzing acceptability of attitudes and behaviors and producing answers to the question: 'how should I/we live' with explaining the rationale of the answers (Rachels 2003). As a study, ethics employs moral standards and justifies its solutions through implementing moral rules and virtues. In this context, ethics includes theories, models, codes, and principles to elucidate right and wrong acts and behaviors. The subjectivity of standards on which ethics is built may make the objectivity and universality of ethics questionable. Nevertheless, because of its essential characteristic, the study of moral philosophy, ethics has to scrutinize and legitimize its "positions through logical, theoretically based arguments" (Rich 2016 p. 4). Therefore, different branches of ethics or different ethical approaches may rely on distinct moral rules and values and reach distinct conclusions. However, the study of these differences has to be done in a scholarly and rational manner. From this perspective, in this paper, ethics is defined as the philosophy analyzing standards and values to determine what is right and wrong and providing answers to the questions: 'how should I/we live and why' as well as 'what should I/we do and why' in light of the aim of minimizing evil and maximizing good. (The firstperson singular, I, is applicable to individual cases, whereas the first-person plural, we, is pertinent to social moral analyses).

\section{Education}

The second component of the phrase ethics education is education. Education is considered to be the best way to promote individual and communal development and the most effective remedy for overcoming many problems, such as ignorance, disparity, and poverty (Burnett 2008). For that reason, education has the potential to produce fascinating outcomes and outputs in individual as well as public level. However, education is not a magical pill that generates fruitful results by itself. The presence of education does not guarantee the solutions of individual and social problems, but good practices could help to alleviate them (Delors et al. 1996). Additionally, without clearly defining education and specifying its goals, it might be difficult to make any comment about the productivity of education.

The dictionary (http://dictionary.cambridge.org 2016) describes education as "the process of teaching or learning." This definition reveals two aspects of education: teaching and learning. Teaching is a concept indicating that a teacher provides the knowledge of something to someone. In other words, the term teaching demonstrates the effort of the teacher about giving knowledge to someone. Although the activity of teaching desires to enlighten, edify, and instruct learners, this process does not ensure that the learners acquire the provided knowledge. A teacher may make her/his best effort in order to inform and train someone without achieving this (Peters 2010). However, learning is the other aspect of education focusing on what the learner gains. Learning requires obtaining certain knowledge and skills with "some understanding of principles, of the "reason why' of things" (Peters 2010 p. 4) According to R.S. Peters (2010), education is not a process that only gives the opportunity of possessing knowledge, but also requires understanding conceptual qualifications. Hirst and Peters 
(2012) state that education "suggests not only that what develops in someone is valuable but also that it involves the development of knowledge and understanding" (p. 19). Hirst and Peters (2012) explain education as the process of possessing knowledge and highlight the purpose of education as "the development of desirable qualities in people" (p. 19). The phrase 'desirable qualities' seems to be too obscure due to the ambiguity in the meaning of desirability and the question of 'being desired by whom.' For this reason, it is believed that expounding on the goal of education as 'developing knowledge and skills' might be more suitable. In some cases, increasing knowledge does not make sense unless the gained knowledge leads to promoting the relevant skills. For instance, having the knowledge of brain surgery does not make a physician a surgeon per se. The physician must also transform this knowledge into surgical skills by training and practicing processes. Therefore, improving skills is a crucial purpose that should be evaluated in the scope of education. Thus the Delors Report acknowledges the significance of improving skills besides knowledge in the process of education (Delors et al. 1996). From this perspectives, in this paper, education is described as the process of improving the learner's knowledge and skills as well as boosting the learner's cognitive development regarding the acquired knowledge and skills.

The World Bank and the United Nations Educational, Scientific, and Cultural Organization (UNESCO) are two international organizations promoting education through their own perspectives. These institutions' views on education bring about two different approaches concerning how to provide educational services and how to improve the efficiency of education. The World Bank's position represents the economist approach of education, while the UNESCO's viewpoint denotes the humanist approach (Barrett et al. 2006).

The World Bank considers education one of the most essential and effective tools in guaranteeing economic growth, peace, and stability as well as decreasing poverty, gender inequality, and economic disparity. In addition, the World Bank provides financial and technical support to requesting countries to "ensure inclusive and equitable quality education and promote lifelong learning opportunities for all" (World Bank Group 2011 p. 1). The World Bank uses a program called Results-Based Financing (RBF) to increase demand for schooling, expand female students participation in school, maintain the number of enrolled students, and boost teaching and learning in countries in which the program is applied. Therefore, the Bank measures the success of the programs by gauging quantitative outcomes, such as schooling, enrollment, and retention percentages (The Rise of Results-Based Financing in Education 2015; Barrett et al. 2006). The focus of the Bank is mainly on the developing countries' educational systems and their challenges involving low schooling rates, inequalities against girls, and poor quality in teaching and learning in terms of acquiring knowledge and basic skills (Education Overview). For these reasons, deeming this approach a convenient model becomes difficult and, therefore, borrowing some aspects of this model to shape ethics education is not feasible.

UNESCO shares the World Bank's vision for education which "[e]nsure[s] inclusive and equitable quality education and promote[s] lifelong learning opportunities for all" (Education 2030 Incheon Declaration... p. iii). However, the World Bank's attention to human capital, economic growth, and quantitative appraisal leaves its place to educational processes, human development, and human right in UNESCO's approach 
(Tikly and Barrett 2011; Barrett et al. 2006). The Bank emphasizes the importance of education by highlighting its functions as "reducing poverty, raising incomes and resilience in the face of crises, and promoting economic growth and shared prosperity" as well as ensuring "sustained investment in human capital" (The Rise of Results-Based Financing in Education 2015 p. 1). On the contrary to the World Bank's economic concerns-based approach, UNESCO puts stress on humanistic aspect of education and details the ability of education as "empower[ing] learners of all ages and equip[ping] them with values, knowledge and skills that are based on and instill[ing] respect for democracy, human rights, social justice, cultural diversity, gender equality and environmental sustainability" (UNESCO Education Strategy 2014-2021 p. 14). This situation demonstrates that even though both approaches have the same vision of education, the dissimilarities in their emphases, assessments, and expectations remarkably differentiate one from the other.

The Delors Report, Learning: The Treasure Within, which was prepared by UNESCO of the International Commission on Education for the Twenty-first Century and published by UNESCO in 1996, is an outstanding work showing UNESCO's view on education. Furthermore, "the Delors Report is widely considered to be a key international reference for the conceptualization of education and learning" (Tawil and Cougoureux 2013 p. 2). (The Report does not only define education as "an ongoing process of improving knowledge and skills," but also broadens the domain of it as "an exceptional means of bringing about personal development and building relationships among individuals, groups and nations" (Delors et al. 1996 p. 12). This position expands the sphere of education as well as gives specific tasks to achieve, like establishing and enhancing relationships among people in all levels of societies and nations. Of course, each educational activity does not carry the potential to accomplish such broad social goals, but this perspective gives the chance to grasp the humanistic function of education and its positive impact on relationships among individuals, groups, and nations. The Report reifies this comprehensive perspective into the four pillars in light of the concept, learning throughout life: learning to know, learning to do, learning to be, and learning to live together (Delors et al. 1996).

Though the Report explains its vision with four pillars, it particularly accentuates the priority of the pillar: learning to live together. This point indicates how the Commission went beyond the traditional role of education as 'the possession of knowledge and skills.' Learning to live together requires recognizing historical, cultural, and religious values of individuals, groups, and nations and developing appropriate methods to wisely administer problems coming from the aforementioned differences in a peaceful manner. This pillar suggests respecting and sustaining individuals' personal and social values rather than converting one's tradition, religion, or style of life into a dominant one. Due to the difficulty of fulfilling the requirements of this pillar, the Report questions whether it is a utopia to have such high ideals. However, the Commission admits this situation as "a necessary Utopia" to overcome "a dangerous cycle sustained by cynicism or by resignation" (Delors et al. 1996 p. 20). It is obvious that educating individuals in accordance with this pillar is not an easy task, but without doing this, the thought of creating a peaceful world would remain a utopia.

Learning to know is about the acquisition of knowledge of different subjects according to scientific, economic, and social necessities. Learning to know represents 
the classical aspect of education as possessing knowledge. The third pillar is learning to do which encompasses boosting certain skills for doing a job. Working is one of the major activities of human beings, and it requires obtaining pertinent qualities and skills. Therefore, the pillar of learning to do denotes getting or improving relevant vocational competencies to be able to do a job and cope with occupational requirements under the circumstances of rapid changes and unexpected conditions. The last pillar of learning throughout life is learning to be which is related to personal development. This pillar demands the exploration and utilization of personal capabilities, such as "memory, reasoning power, imagination, physical ability, aesthetic sense, the aptitude to communicate with others and the natural charisma of the group leader" (Delors et al. $1996 \mathrm{p}$. 21). In this sense, education does not merely imply the gain of something from the outside of the person, but also entails discovering the person's internal abilities.

As a result, in case of comparing the Delors Report's definition of education with its pillars, it may be deduced that:

- 'Improving knowledge and skills' represents learning to know and learning to do,

- 'Bringing about personal development' denotes learning to be, and

- 'Building relationships among individuals, groups and nations' indicates learning to live together.

Humanistic approach of education provides an all-inclusive and meaningful insight of learning, emphasizes the importance of understanding cultural, religious, and political differences, and demonstrates the necessity of finding peaceful ways to live together. Especially, the issue of learning to live together is an exceptional point for being able to manage the challenges and conflicts of the multicultural world as well as drawing a conceptual framework for ethics education. The existing diversity in cultural, religious, and philosophical viewpoints generates several distinct moral values, and reconciling these differences requires a well-educated as well as a receptive mindset and ethical outlook.

\section{Ethics education}

In the first section, the concepts of ethics and education have been evaluated. Ethics was described as the philosophy analyzing standards and values to determine what is right and wrong and providing answers to the questions: 'how should I/we live and why' as well as 'what should I/we do and why' in light of the aim of minimizing evil and maximizing good, whereas education was defined as the process of improving the learner's knowledge and skills as well as boosting the learner's cognitive development regarding the acquired knowledge and skills. In light of these definitions, in this section, the notion and some approaches of ethics education will be examined.

\section{The concept of ethics education}

UNESCO is one of the few international organizations closely engaging in ethics education. UNESCO's first involvement in teaching ethics was the World Conference 
on Science and the Use of Scientific Knowledge in 1999. In the Declaration of the Conference, all scientists were invited to follow ethical codes and standards in light of international human rights. Moreover, the Declaration recommended adding ethics to science curricula (COMEST The Teaching of Ethics). As a result of UNESCO's continuous interest and the member countries' request, ethics and teaching ethicsrelated studies and activities were advanced, and the World Commission on the Ethics of Scientific Knowledge and Technology (COMEST) published a report in 2003 entitled the Teaching of Ethics (ten Have 2008). The Report stresses the significance of teaching ethics by stating that " $[\mathrm{t}]$ he study of ethics is important not only for our individual lives, but also for developing the insight and competence we as a community need in order to face the challenges of the present and the future in a reasonably successful way" (COMEST The Teaching of Ethics p. 8). Furthermore, the Report summarizes the reasons increasing interest in ethics. These reasons include rapid changes, rising contact among different cultures, developments in the Internet and media, deteriorations in traditions, advances in science and technology, increasing environmental concerns, and improvements in gene technology, which have raised the importance of teaching ethics (COMEST The Teaching of Ethics).

The necessity of ethics education or teaching ethics (as interchangeable phrases) has been recognized at the United Nations' level since the 1990s. Nevertheless, this recognition does not resolve all challenges by itself. For example, in a nutshell, ethics education may be regarded as teaching or learning of moral values, rules, and principles. However, one of the questions is whether it is sufficient to transfer ethical knowledge for instilling ethical conduct. Gordijn and ten Have (2013) query this issue through comparing Socrates' and Aristotle's views on the relationship between the acquisition of knowledge and the demonstration of ethical behavior. Gordijn and ten Have (2013) interpret Aristotle's stand more realistic than Socrates' stance; the former does not consider knowledge an adequate factor for displaying virtuous conduct, while the latter assumes the presence of knowledge sufficient for exhibiting ethical behavior. Even though the authors admit that ethics education does not only consist of the possession of knowledge and find it doubtful that there is a direct proportion between teaching ethics and moral act, they take the position in favor of teaching ethics.

Michael Wright (1995) reviews literature to determine whether there is a link between ethics education and ethical behavior. Wright (1995) is proponent of supporting the idea that "education is the best means of developing good ethical behaviour," but the review does not give enough evidence that ethics education explicitly improves moral conduct (p. 17). Another literature review conducted by Cannaerts, Gastmans and Dierckx de Casterle (2014) gauges nursing students' and educators' viewpoints about the impact of ethics education on nursing students. The review indicates that students and educators believe that ethics education increases students' "ethical perceptive, reflective, and decision making skills. However, they barely mention the contribution of ethics education to the development of ethical behavior in nursing practice" (Cannaerts, Gastmans and Casterle 2014 p. 874). The literature review reveals that teaching ethics creates certain improvements in students' ethical knowledge, sensitivity, and skills, but its contribution to virtuous conduct is not obvious enough. 
Schwitzgebel and his colleagues (2012) observed the behavior of audiences during four meetings of the American Philosophical Association in 2008 and 2009 to examine the courtesy of the participants and decide whether the behavior of philosophers attending ethics sessions was morally better than the behavior of philosophers attending non-ethics sessions. The hypothesis was that "professional ethicists would behave morally better than ... socially comparable non-ethicists," and it was tested by assessing the behavior of the participants (Schwitzgebel et al. 2012 p. 331). They examined whether participants talked loudly during the sessions, let the door slam when entering or leaving the sessions, and left trash and cups behind at the end of the sessions. However, the results of the three measures did not demonstrate a significant difference between the courtesy of ethics philosophers and non-ethics philosophers. In other words, the hypothesis that the engagement in ethics would improve moral behavior was not supported by the results (Schwitzgebel et al. 2012).

This situation may be illuminated by three suppositions. First, as the aforementioned studies show, ethics education does not directly develop ethical behavior. Second, a correlation between teaching ethics and virtuous conduct may exist, but shortages or shortcomings of ethics education preclude the emergence of possible positive consequences. Third, there are methodological defects of the research seeking to prove the influence of teaching ethics on moral behavior. However, instead of choosing one of these options, maybe some other questions should be asked, such as 'should ethics education change individuals' character or behavior?', is it an ethical and real expectation to desire to change one's character, especially in adult education?', or 'does the teaching of ethics differ from the teaching of other subjects?', and so on.

In terms of the method of teaching ethics, Bayard L. Catron (1989) underlines a close relationship between ethics and conduct and claims that the teaching of ethics is not different from the teaching of other subjects. Catron (1989) looks at teaching ethics as conveying the knowledge of ethics and likens the role of ethics professors to retailers who sell knowledge. In the Vocation Lectures, Max Weber (2004) explains young American students' attitudes by their tendency to equate a teacher's effort to that of a greengrocer's work; the former sells knowledge, while the latter sells cabbage. Weber (2004) emphasizes the students' expectation of teachers being leaders in their fields. Nevertheless, Weber (2004) calls to his students as:

Fellow students! You come to our lectures with the expectation that we will be leaders, but you do not say to yourselves beforehand that out of one hundred professors, at least ninety-nine ... neither claim, nor have any right to claim, to be "leaders" of any kind in matters of conduct (p. 25).

From this perspective, if a professor in management is not expected to be an outstanding leader, if a professor in economics is not expected to be a successful $\mathrm{CEO}$, or if a professor in political science is not expected to be an inspiring politician, why is a professor in ethics supposed to be a role model of virtuous behavior? Moreover, why is the teaching of ethics considered more complex than the teaching of other subjects? In light of Weber's and Catron's approaches, an ethicist or a professor in ethics is merely a person selling her/his knowledge, like other professors in other academics disciplines.

It is an ideal situation to expect behavioral changes or influences from education. However, expertise in knowledge does not bring about expertise in practice per se. For 
example, being an exceptional soccer player does not mean to be an excellent soccer coach, and vice versa because each person cannot successfully transfer knowledge into practice. This circumstance is valid for all academics areas including teaching ethics. As the research carried out by Schwitzgebel and his colleagues (2012) shows, if ethics education does not engender a remarkable difference in ethics professors' moral conduct, how would it be realistic to expect changes in ethical behavior of students/ individuals with limited knowledge of ethics? Of course, teaching ethics may create perfect role models of virtuous conduct, but lack of this should not be regarded as the failure of ethics education. The expectation of changes in ethical behavior points out the desire for character education which is a traditional approach in moral education (Narvaez 2006).

\section{Some approaches about ethics education}

The issue of whether education should instill a particular moral character is one of the essential subjects of ethics education. The response to this circumstance is directly related to the apprehension of the role of teaching ethics. UNESCO's COMEST Report delineates the aim of ethics study as follows:

- the study should increase the students' awareness of ethical issues

- provide a deep understanding of ethical matters and greater clarity in ethical questions

- place ethical problems in a wider context and make explicit the alternatives that we may choose from, and how their various positive and negative consequences are experienced by those who are affected

- develop the skill for ethical analysis and argumentation

- determine areas where social practice or legislation is at odds with ethical standpoints which seem to be well-founded (p. 11).

Therefore, even though the Report calls attention to the improvements in ethical awareness, the insight of ethical issues, and the judgement of ethical problems, it does not mention the necessity of any character changes.

Darcia Narvaez (2006) touches on two major approaches in ethics education, traditional character education and rational moral education, and suggests a third approach as integrative ethical education for shaping the moral development of children. According to Lapsley and Narvaez (2006), the moral formation of children is a classic objective of formal education. However, children's first educational institutions and their first teachers are their parents who inculcate in the children certain moral values (Gutmann 1999). Therefore, not just formal education, but also informal education aims to contribute to childhood moral development. Nonetheless, traditional character education does not represent a liberal moral formation of individuals; it denotes the transmission of packaged moral norms, which may come from the family's, school's, church's, or state's moral acceptances, and the compliance with these norms (Lapsley and Narvaez 2006).

The second approach Narvaez (2006) mentions is rational moral education, also known as the cognitive-developmental approach, which "seeks to facilitate the 
development of autonomous moral judgement and the ability to resolve disputes and reach consensus according to canons of fairness" (p. 703). Traditional character education tries to instill in individuals a particular morality, whereas rational moral education strives to teach individuals how to establish good moral character without imposing a specific morality. The former limits the learner to a ready-made moral system, but the latter empowers the learner to discover all moral systems and build her/ his own moral character. For this reason, in traditional character education, the educator aims to directly shape the learner's moral acceptances, while in rational moral education, the educator only helps the learner to improve her/him moral judgement. Traditional character education might be criticized due to its authoritarian aspects, and rational moral education could be denounced because of not containing certain moral perspectives (Narvaez 2006).

Another approach concerning teaching ethics is ethical acculturation proposed by Handelsman, Gottlieb, and Knapp (2005). They adapt John W. Berry's acculturation concept to ethics training. Handelsman and his colleagues (2005) liken the process of psychologists learning ethics to the reactions of a person encountering a new culture. Berry (1997) states that in multicultural societies, the members and groups of dominant as well as non-dominant cultures must pay attention to cross-cultural understandings and influences. According to Berry (1997), when individuals and groups from distinct cultures meet, in light of cultural maintenance as well as contact and participation, one of the four possibilities of acculturation occurs: assimilation, separation, integration, or marginalization. Cultural maintenance shows the insistence on the continuation of the existing culture, and contact and participation exhibits the interaction among culturally dissimilar individuals and groups. Assimilation and separation depend on how individuals and groups encounter and interact with individuals and groups from other cultures. Exhibiting low cultural maintenance and desiring high interaction with others demonstrates assimilation, while a preference for high cultural maintenance and little or no interaction with others indicates separation. On the other hand, integration and marginalization reveal the level of unification of cultures and interests in having a relationship with others. Integration implies a balance between maintaining the existing culture and internalizing the new culture as well as a high interest in communicating with others, whereas marginalization points out little or no cultural maintenance as well as little or no relationship with individuals and groups from other cultures.

The ethical acculturation model focuses on the process of ethics training of graduate students in psychology who have already learnt some professional behaviors and values. Furthermore, this model considers ethics training to be more complicated than merely teaching or learning ethical norms. Handelsman, Gottlieb, and Knapp (2005) equate the existing ethics knowledge of graduate students who desire to become psychologists with the experience of individuals who enter a new culture. This approach asserts that similar to individuals encountering new cultures, psychologist candidates must experience the process of ethical acculturation to develop their ethical knowledge, behavior, and skills (Handelsman, Gottlieb and Knapp 2005). Cultural maintenance, in ethical acculturation, denotes students' reliance on "preexisting notions of right and wrong professional behavior," and the matter of contact and participation represents "the APA Ethical Standards and other indicators of psychology ethics" (Bashe et al. 2007 p. 61). In other words, maintenance refers to students' assuming 
the sufficiency of their own personal values and contact, whereas participation means their increased awareness of professional ethics, norms, and standards.

Like cultural acculturation, ethical acculturation has four strategies emerging in accordance with the relationship between maintenance and contact. In ethical acculturation, integration is the most desired strategy, demonstrating students' high tendency to maintain their preexisting values and high interest in new professional standards, which "represents the most consistency or coherence between personal and professional identities and values" (Bashe et al. 2007 p. 61). Contrary to integration, marginalization which indicates a low interest in personal morality and professional values is the least popular strategy due to denoting the lack of personal as well as professional moral development (Gottlieb, Handelsman and Knapp 2008). The third strategy is assimilation which represents students' indifference to their own moral values and high enthusiasm for professional identity. Under the presence of assimilation, individuals give up their own ethical standards and completely internalize professional rules. Handelsman and his colleagues (2005) regard this strategy as dangerous for students because of the possibility of causing "empty, legalistic, and overly simplistic applications of our ethical principles" (p. 61). The last strategy of ethical acculturation is separation exhibiting a high concentration on personal moral acceptances with the negligence in ethical principles and rules of the profession. This strategy may also lead to detrimental consequences due to not understanding the importance and necessity of applying professional standards (Handelsman, Gottlieb and Knapp 2005).

The ethical acculturation model acknowledges the strategy of integration as the ideal situation. Ethical acculturation aims to integrate individuals' preexisting personal and professional identities into new professional rules, principles, and values. The students' previous moral standards are respected, and the students are requested to be aware of their own personal, cultural, and professional backgrounds, but they are also required to internalize the ethical codes, values, and principles of the profession they want to enter. Therefore, assimilation, separation, and marginalization are deemed problematic strategies; ethical acculturation is defined in the scope of the strategy of integration as an ongoing process giving the student "an opportunity to identify and clarify their personal, cultural, and family of origin values and to consider how these will align with the new or changing professional culture" (Bashe et al. 2007 p. 62). In this sense, the ethical acculturation model accepts ethics education not only as the teaching or learning of a list of ethical codes and rules, but also as "a process of developing and maintaining a professional identity" through integrating the participants previous individual cultures and experiences into the professional moral requirements (Bashe et al. 2007 p. 61).

However, the convenience of transition from the preexisting culture to the new one may not be as easy as expected. Gottlieb and his colleagues (2008) draw attention to this issue. They state that in the event of too much gap between personal and professional cultures, some students might implement the strategy of assimilation to be able to accommodate themselves to the new professional qualifications. Nevertheless, remarkable conflicts between the students' previous moral systems and the new professional culture may cause the appearance of separation and marginalization strategies as well. Assimilation indicates a reaction welcoming the new professional identify. However, the reaction deriving from the cultural conflict may come out as rejecting this new identify, so separation and marginalization are also likely 
possibilities in the case of high inconsistency between previous and new conditions. For such cultural distance-based challenges, Gottlieb and his colleagues (2008) suggest an early detection of the problem and its magnitude as well as the students' eagerness and capability to adopt integration.

According to Bashe et al. (2007), the ethical acculturation model has four benefits. First, this model emphasizes the significance of ethics in professional identity and the essentiality of refurbishing ethical knowledge. Second, ethical acculturation does not impose an assimilating strategy; on the contrary, it recognizes the worthiness of personal experiences and values. Third, ethical acculturation is regarded as an ongoing process, hence individuals remain active in the integration between their personal virtues and their professional standards. Fourth, this model represents a journey starting by identifying personal values and professional needs and ending by integrating personal and professional identities. Therefore, ethical acculturation provides a progressive development for ethics education.

In case of comparing the ethical acculturation model with the character education approaches (traditional character education and rational moral education), it may be said that some advantages and disadvantages of each can be mentioned. However, one of the main differences between the ethical acculturation model and character education approaches is the distinction between their primary groups; the ethical acculturation model is established on the idea of acculturating graduate students who choose to be psychologists, whereas the character education approaches focus on the moral development of children. The former tries to increase ethical knowledge and skills of already educated adults in light of professional requirements, while the latter strives to discover the most appropriate way to form or shape the character of children according to moral values (Handelsman, Gottlieb and Knapp 2005; Narvaez 2006). From this perspective, in terms of the target groups, the ethical acculturation model seems to suit ethics education in healthcare more than character education approaches. Furthermore, the essential feature of ethical acculturation which requires integrating personal values into professional identity is a superiority of this method. The combination of respecting the differences in individuals' cultural backgrounds and experiences and recognizing the necessity of professional moral standards is crucial in teaching ethics in professions. On the other hand, the liberal aspect of rational moral education which "is concerned with the development of reasoning and autonomy" also exhibits potential for proposing/forming a new model for ethics education in healthcare (Narvaez 2006 p. 703).

\section{The goals of ethics education}

In the first section, the concepts of ethics, education, and ethics education were explained to clarify what these terms imply. Furthermore, in the second section, two major approaches in education, traditional character education and rational moral education, as well as the ethical acculturation model suggested by Handelsman and his colleagues were succinctly expounded. In this section, some important issues will be highlighted in light of the acquired ideas from the earlier sections, and then the goals of ethics education in healthcare will be proposed. 


\section{How to understand ethics education}

Prior to delineating the goals of ethics education, underlining some points in light of the matters mentioned in the above sections would be beneficial. First, ethics education is a very broad concept pertinent to all academic disciplines. Even though it may be probable to outline certain objectives of teaching ethics available for more than one academic area, due to the unique characteristics and requirements of each field, focusing on a specific discipline would give the opportunity to address more definite goals. For this reason, in this paper, ethics education refers to the teaching of ethics in healthcare which can also be named as bioethics education. Henk ten Have (2014) defines bioethics as "the discipline that is focusing on ethical issues in medicine, health care, and associated technologies" (p. 447). Indeed, though bioethics may be evaluated as conceptually more comprehensive than healthcare ethics, in the scope of the present article, the terms 'ethics education in healthcare' and 'bioethics education' are regarded as interchangeable.

Second, the term 'healthcare' covers many professionals including physicians, nurses, pharmacists, therapists, psychologists, and so on. In this view, healthcare ethics/bioethics does not denote a particular profession, but all healthcare professions. According to Grob, Leng and Gallagher (2012), "[p]rofessional ethics relates to the values and standards of a particular profession, which are generally made explicit in professional codes of conduct or practice" (p. 36). In this context, bioethics education does not imply any type of professional ethics, but indicates ethics teaching to any person who decides to enter a profession in healthcare.

Third, ethics education is an ongoing process improving the learner's ethical knowledge and skills as well as enhancing the learner's ethical cognitive development regarding the acquired knowledge and skills. In this view, ethics education aims to stimulate some changes in learners' ethical knowledge, perception, and perspective. However, these changes do not suggest an assimilation process. Cultural assimilation means to abandon the preexisting cultural identity, and ethical assimilation implies to leave the previous morality (Berry 1997; Handelsman, Gottlieb and Knapp 2005). Ethics education should be understood as the integration between preexisting moral values and new professional ethical standards. The research study conducted by Rodríguez et al. (2014) containing a survey of 136 ethics instructors from American Psychological Association (APA) accredited programs in the United States and Canada demonstrates that more than $86 \%$ of the educators specify the aims of ethics education as 'advancing critical thinking', 'preparing students to use ethical decision making models', 'providing specific information and resources on ethics', and 'teaching the ability to make difficult decisions.' From this perspective, ethics education should not impose a specific morality on learners; it should teach the relevant ethical theories, norms, and principles to learn how to think critically and make ethical assessments and autonomous decisions (Bashe et al. 2007). For example, in terms of the beginning of life issues, bioethics education should not insist on pro-life or pro-choice arguments. It should teach all aspects of the arguments, pertinent moral theories, and ethical principles as well as appropriate methods for making morally acceptable judgements in accordance with cultural, religious, and philosophical backgrounds.

Fourth, bioethics education is not traditional character education. Traditional character education is a widespread, but also a contentious approach aiming to design 
children's moral personality (Lapsley and Narvaez 2006). "For traditional character education, morality is ready-made and good character requires submission to its preexisting norms" (Lapsley and Narvaez 2006 p. 261). On the other hand, bioethics education intends to increase healthcare professionals' knowledge and skills to identify ethical issues and make ethical judgements (Thornton, Callahan and Nelson 1993). Therefore, traditional character education focuses on children's moral development, whereas bioethics education concentrates on the teaching ethics of healthcare professionals. Moreover, the former imposes a particular morality and requests obedience, while the latter tries to enhance ethical awareness and moral reasoning. In this view, it is believed that bioethics education does not have a function to form a new character. The improvement of ethical knowledge and skills may influence the individuals' personal behaviors in a positive manner. However, the effectiveness of ethics education should not be measured by non-profession-related behaviors or activities; it should be gauged by the adaptation to professional moral requirements as well as by the ability of ethical awareness, ethical analysis, and moral judgement in professional implementations.

Finally, bioethics education may be formulated in the scope of the rational moral education approach and the integration strategy of the acculturation model. Even though rational moral education is related to the moral development of children, its neutral aspect aiming to teach morality in an impartial manner and its indirect feature considering educators solely the facilitators of moral development may be applicable to bioethics education to create a liberal and humanistic teaching environment (Narvaez 2006). Moreover, the perspective of the integration strategy of ethical acculturation produces a useful approach to emphasize the significance of the consolidation of personal moral values and professional ethical qualifications (Bashe et al. 2007). Furthermore, the view of recognizing and respecting individual moral differences and diverse experiences could facilitate the development of global bioethics which focuses on "the ethical concerns of humanity" worldwide and "contains "the ethical values and principles of various populations without assuming that one specific set of values and principles is dominant." (ten Have 2016 p. 9) In this context, bioethics education is not limited to any particular moral system; rather, it encompasses the teaching of all moral aspects and promotes the improvement of ethical awareness, thinking, and judgement through the integration of personal and professional moral acceptances.

\section{The goals of ethics education}

Outlining the goals of ethics education is crucial to accurately describe its concept and determine its scope. Because of this reason, almost every paper examining ethics education addresses certain goals. For instance, Li-Ling Hsu (2011) points out the purpose of ethics education in nursing as producing "morally accountable nurses" ( $p$. 419). Similarly, Sudhir K. Chawla and his colleagues (2015) identify the aim of ethics education in accounting as producing "ethical professionals" (p. 18). Moreover, Henk ten Have (2014) accentuates the consensus on the eventual objective of ethics education in bioethics as producing "good health professionals and scientists" (p. 458). These statements suggest that an important goal of ethics education may be to produce good, ethical professionals.

According to Cubie L. L. Lau (2010), the aim of ethics education in business is "to help students to be more aware and sensitive to the ethical consequences of their actions" 
(p. 569). Sanders and Hoffman (2010) express the main goals of ethics education in social work as improving moral judgement, which indicates how to deal with ethical conflicts, and moral sensitivity. These goals show the ability of pinpointing ethical issues. Mihyun Park et al. (2012) regard the objective of ethics education in nursing as "to develop among students the necessary skills for ethical decision making: moral sensitivity and moral reasoning" (p. 569). Thornton, Callahan, and Nelson (1993) enumerate the goals of ethics education in bioethics as "(1) to stimulate the moral imagination, (2) to recognize ethical issues, (3) to develop analytical skills, (4) to elicit a sense of moral obligation and personal responsibility, and (5) to tolerate and resist disagreement and ambiguity" (p. 27). Even though each of the aforementioned studies evaluates teaching ethics in a different discipline or profession, they mostly agree on improving ethical awareness, sensitivity, and judgement to identify, analyze, and resolve ethical issues and conflicts.

All the mentioned interpretations reveal essential elements of ethics education and its goals. Nevertheless, in this paper, the objectives of ethics education will be elaborated in light of the four pillars of the Delors Report. In other words, the four pillars of the lifelong education approach will be adapted to the determination of the goals of ethics education. The concept of lifelong education which is also named as 'learning throughout life' was counted as a guiding principle requiring individuals to "be in a position to keep learning throughout [their] life" by UNESCO's Faure Commission Report (Faure et al. 1972 p. 181) The Delors Report re-evaluated and broadened the concept of lifelong education in order to deal with rapid changes and advances as well as new situations (Delors et al. 1996). The concept of lifelong education is parallel to the perspective of ethical acculturation which deems ethics learning as an ongoing process. Moreover, there is a similarity between the reasons behind the concept of lifelong education and the arguments counting ethical acculturation an as ongoing process. The ethical acculturation model requires individuals to keep continuing their ethical training throughout their professional lives due to the ongoing changes (Handelsman, Gottlieb and Knapp 2005). Therefore, the precondition of adapting the pillars of the concept of learning throughout life to ethics education is to acknowledge teaching ethics as an ongoing process throughout learners' professional lives. For overcoming the continuous changes in healthcare and healthcare-related areas, healthcare professionals should proceed with their ethics education as long as they practice their professions. In this view, the goals of ethics education are as follows:

- to increase ethical knowledge (learning to know),

- to improve ethical skills to strengthen ethical sensitivity, awareness, and judgement (learning to do),

- $\quad$ to develop ethical behavior (learning to be),

- to promote cultural competence (learning to live together).

\section{Increasing ethical knowledge as learning to know}

The acquisition of knowledge is not only the first goal of ethics education, but also the initial objective of all kinds of education. Some approaches may attribute further qualities to education, but there is a consensus among them that the primary function of education 
is to gain knowledge (Peters 2010). This criterion is also valid for ethics education. For instance, Campbell, Chin, and Voo (2007) explain the goals, assessment methods, and outcomes of medical ethics education through a three-level ascending pyramid, the first level of which is knowledge. Similarly, Sudhir K. Chawla et al. (2015) define the initial goal of an ethics course as to "[d] eliver a common body of knowledge in ethics" (p. 19). Furthermore, Henk ten Have (2014) underscores the weight of knowledge in the understanding of ethical issues.

This goal of ethics education refers to the possession and increase of the information about ethics-related subjects. Learning ethical theories, rules, principles, codes, and other applicable ethical information are related to this objective. Ethics education has the task to identify, analyze, and resolve ethical issues and conflicts. Having adequate ethical knowledge is the necessary, but not sufficient, condition of fulfilling the task. For this reason, ethics education must provide satisfactory ethical information to be able to establish or improve other pertinent considerations, such as developing ethical skills. From this perspective, in terms of adapting the concept of learning throughout life to ethics education, 'improving ethical knowledge' matches 'learning to know' which requires "combining a sufficiently broad general knowledge with the opportunity to work in depth on a small number of subjects. This also means learning to learn, so as to benefit from the opportunities education provides throughout life" (Delors et al. 1996 p.37). In this view, ethics education should aim to supply adequate information to know relevant subjects and concepts.

\section{Improving ethical skills to strengthen ethical sensitivity, awareness, and judgement as learning to do}

As aforementioned, acquiring or increasing ethical knowledge is the first step of ethics education. However, the presence of knowledge is not sufficient per se to identify, analyze, and resolve ethical matters and challenges. The ability to stimulate knowledge and transform it into actions is also certainly important and necessary. Henk ten Have (2014) gives an example to clarify the relationship between knowledge and skills and says that "if the focus is on informed consent, students should know what it is; they should have information and facts about this concept, but they should also learn how to apply it in practice" (p. 452-453). Therefore, besides ethical knowledge, ethics education should provide the opportunity to improve ethics-related skills: ethical sensitivity, ethical awareness, and ethical judgement. Catherine Robichaux (2012) states that in the event of creating a learning-friendly environment, ethical skills can be taught through ethics education. In this context, many authors, such as Jensen and Greenfield (2012) as well as Mihyun Park et al. (2012) recognize the development of skills an essential purpose of ethics education.

The aim of strengthening ethical skills is to gain or increase the ability of learning to do a job, as highlighted by the concept of learning throughout life. Ethics education should enhance healthcare professionals' skills to improve their ethical sensitivity, awareness, and judgement. Developing the pertinent skills is significant not only to meet daily routines of the professions, but also to deal with unexpected ethical circumstances (Delors et al. 1996). Additionally, the acquisition or improvement of skills needs long-term training, hence the teaching of ethics should be accepted as a process, in terms of strengthening skills as well. 
As previously elaborated, ethics education does not refer to traditional character education. Therefore, in principle, teaching ethics does not necessitate forming virtuous character of behavior. Moreover, according to several studies, it is questionable whether ethics education creates moral behavior (Gordijn and ten Have 2013; Wright 1995; Cannaerts, Gastmans and Casterle 2014). However, at that point, the idea of generating a virtuous character should be differentiated from the view of influencing professional behavior. For instance, constantly instilling in a child not lying in life because of negative consequences may be considered a character formation, whereas taking a healthcare professional's attention not to lie in the relationship with patients due to their rights to accurate informed consent could be regarded as professional behavioral improvement. In this view, the goal of improving ethical behavior implies to promote professional moral behavior rather than one's general character. Of course, helping to create more appropriate behaviors in one's life may be desirable, but it should not be counted as one of the objectives of ethics education in healthcare because of the professional aspect of bioethics.

Furthermore, improving ethical behavior is formulated in light of learning throughout life concept's third pillar: learning to be. Learning to be suggests improving one's personality and discovering her/his potential, like "memory, reasoning, aesthetic sense, physical capacities and communication skills" (Delors et al. 1996 p. 37) In case of the adaptation of this approach to bioethics education, it can be emphasized that the development of professional ethical behavior should be fulfilled not only through improving ethical knowledge and skills, but also through exploring and promoting individual potential.

\section{Promoting cultural competence as learning to live together}

Cultural competence implies beliefs, attitudes, behaviors, and policies facilitating a compatible togetherness in a cross-cultural environment (Chin 2000; Anderson et al. 2003). According to Gregory Juckett (2005), cultural competence refers to "possessing knowledge, awareness, and respect for other cultures" and requires recognizing cultural differences and respecting their own characteristics (p. 2267). Cultural, religious, and social diversity in healthcare as well as in all levels of multicultural societies necessitates finding a peaceful way to prevent cultural assimilation as well as cultural separation or marginalization. In this view, the integration strategy of ethical acculturation provides an outstanding aspect to encourage the survival of moral differences in an integrated structure (Bashe et al. 2007). This facet of ethics education should be strengthened by the perspective of 'learning to live together.' The Delors Report emphasizes the function of learning to live together as;

by developing an understanding of others and their history, traditions and spiritual values and, on this basis, creating a new spirit which, guided by recognition of our growing interdependence and a common analysis of the risks and challenges of the future, would induce people to implement common projects or to manage the inevitable conflicts in an intelligent and peaceful way. Utopia, some might think, but it is a necessary Utopia, indeed a vital one if we are to escape from a 
dangerous cycle sustained by cynicism or by resignation (Delors et al. $1996 \mathrm{p}$. 20).

Regardless of being a utopia or not, the underscored understanding should be reflected to ethics education in order to transcend the teaching or learning of a list of ethical codes, rules, and principles. For this reason, it is absolutely believed that promoting cultural competence is a primary goal of ethics education.

Increasing ethical knowledge and improving ethical skills to strengthen ethical sensitivity, awareness, and judgement are classic goals of ethics education emphasized by almost all studies which inquire into the aims of teaching ethics. However, the cultural, religious, and social diversity bolstering a cultural competence-based approach is the unique characteristic of the present study. As an idea as well as an ideal, endorsing diversity is not a new view, but recognizing the importance of diversity as a central goal of ethics education is an original perspective. For example, 'respect for cultural diversity and pluralism' is one of the primary principles of the UNESCO Universal Declaration on Bioethics and Human Rights (UDBHR), which was declared in 2005. The UDBHR underlines the significance of diversity and pluralism as a universal principle and requests respecting this value in light of human dignity and human rights (Universal Declaration on Bioethics and Human Rights 2009). Therefore, formulating the goals of ethics education as encompassing the promotion of cultural competence is not an extreme approach; on the contrary, it is a requirement of the UDBHR's vision and principles.

\section{Conclusion}

In light of the basic principles of Kohlberg's cognitive-developmental approach (the rational moral education approach), Handelsman et al.'s ethical acculturation model, and the Delors Report's learning throughout life concept, the conceptual framework of ethics education and its goals were examined. These three perspectives were integrated to determine the notion of teaching ethics and its objectives. Rational moral education demonstrates the role of educators in teaching ethics which demands providing learners all aspects, ideas, and approaches of ethics without imposing a specific one on learners. Ethical acculturation represents learners' position in ethics learning which requires integration between learners' preexisting moral values and new professional requirements. Learning throughout life denotes the precondition of ethics education as an ongoing process. Under the general perspectives of these three approaches and the adaptation of the four pillars of the Delors Report to teaching ethics, the goals of ethics education were defined as increasing ethical knowledge; improving ethical skills to strengthen ethical sensitivity, awareness, and judgement; developing ethical behavior; and promoting cultural competence. Assessing ethics education with the aforementioned objectives would not only give the opportunity to improve learners' ethical knowledge and skills to identify, analyze, and resolve ethical issues and conflicts through the development in ethical sensitivity, awareness, and judgement, but also it would provide the chance to discover and appreciate individuals' potentials, personal values, and peaceful ways to live together by enhancing cultural competence. 


\section{References}

Anderson, L.M., et al. 2003. Culturally competent healthcare systems. A systematic review. American Journal of Preventive Medicine 24(3 Suppl): 68-79.

Avci, E. 2016. Learning from experiences to determine quality in ethics education. International Journal of Ethics Education. doi:10.1007/s40889-016-0027-6.

Barrett, A.M., et al. 2006. The Concept of Quality in Education: A Review of the 'International' Literature on the Concept of Quality in Education, 2-3. Bristol: EdQual RPC.

Bashe, A., et al. 2007. An acculturation model for ethics training: the ethics autobiography and beyond. Professional Psychology: Research and Practice 38(1): 60-67.

Bendik-Keymer, J. 2013. The Moral and the Ethical: What Conscience Teaches Us about Morality" in Morality: Reasoning on Different Approaches, ed. Vasil Gluchman, 11-23. Amsterdam: Rodopi, eBook \& Streaming Video Collection (Gumberg Library), EBSCOhost (accessed September 1, 2016).

Berry, J.W. 1997. Immigration, acculturation, and adaptation. Applied Psychology: An International Review 46: 5-68.

Boon, H. 2011. Raising the bar: ethics education for quality teachers. Australian Journal of Teacher Education 36(7): 76-93.

Burnett, N. 2008. The delors report: a guide towards education for all. European Journal of Education 43(2): 181187.

Campbell, A.V., J. Chin, and T.-C. Voo. 2007. How can we know that ethics education produces ethical doctors? Medical Teacher 29: 431-436.

Canary, H.E., et al. 2014. Engaging students in integrated ethics education: a communication in the disciplines study of pedagogy and students' roles in society. Communication Education 63(2): 83-104.

Cannaert, N., C. Gastmans, and B. Dierckx de Casterle. 2014. Contribution of ethics education to the ethical competence of nursing students: educators' and students' perceptions. Nursing Ethics 21(8): 861-878.

Catron, B.L. 1989. Teaching ethics, teaching ethically. Policy Studies Review 8(4): 865-870.

Chawla, S.K., et al. 2015. Evaluating ethics education for accounting students. Management Accounting Quarterly 16(2): 16-25.

Chin, J.L. 2000. Culturally competent health care. Public Health Report 115(1): 25-33.

COMEST The Teaching of Ethics, UNESCO, accessed September 10, 2016, http://unesdoc.unesco. org/images/0013/001345/134552mb.pdf.

Delors, J., et al. 1996. Learning: The Treasure Within. Paris: UNESCO Publishing.

Domenech Rodríguez, M.M., et al. 2014. Ethics education in professional psychology: a survey of american psychological association accredited programs. Training and Education in Professional Psychology 8(4): 241247.

Education 2030 Incheon Declaration Towards Inclusive and Equitable Quality Education and Lifelong Learning for All, UNESCO, accessed September 7, 2016, http://unesdoc.unesco.org/images/0024 /002432/243278e.pdf.

Education, Cambridge Dictionary, accessed September 3, 2016, http://dictionary.cambridge. org/dictionary/english/education.

Education Overview, World Bank Group, accessed September 5, 2016, http://pubdocs.worldbank. org/en/890441459784763164/EDUCATION-OVERVIEW-April4.pdf.

Ethics, Cambridge Dictionary, accessed September 1, 2016, http://dictionary.cambridge. org/dictionary/english/ethics.

Faure, E., et al. 1972. Learning to Be: The World of Education Today and Tomorrow. Paris: UNESCO.

Gert, B. 2005. Morality: Its Nature and Justification, (Oxford; New York: Oxford University Press), eBook \& Streaming Video Collection (Gumberg Library), EBSCOhost (accessed September 3, 2016).

Gordijn, B., and H. ten Have. 2013. Quandaries of ethics education. Med Health Care and Philos 1-2.

Gottlieb, M.C., M.M. Handelsman, and S. Knapp. 2008. Some principles for ethics education: implementing the acculturation model. Training and Education in Professional Psychology 2(3): 123-128.

Grob, C., J. Leng, and A. Gallagher. 2012. Educational responses to unethical healthcare practice. Nursing Standard 26(41): 35-41.

Gutmann, A. 1999. Democratic Education: With a New Preface and Epilogue (Princeton; Chichester: Princeton University Press, eBook \& Streaming Video Collection (Gumberg Library), EBSCOhost (accessed September 12, 2016).

Handelsman, M.M., M.C. Gottlieb, and S. Knapp. 2005. Training ethical psychologists: an acculturation model. Professional Psychology: Research and Practice 36(1): 59-65.

Hirst, P.H., and R.S. Peters. 2012. The Logic of Education. New York: Routledge. 
Hsu, L.-L. 2011. Blended learning in ethics education: a survey of nursing students. Nursing Ethics 18(3): 418-430.

Jensen, G.M., and B. Greenfield. 2012. Ethics education: developing habits of mind through the use of pedagogical content knowledge. Physical Therapy Reviews 17(3): 149-156.

Juckett, G. 2005. Cross-cultural medicine. American Family Physician 72(11): 2267-2274.

LaFollette, H. 2014. Theorizing About Ethics, in Ethics in Practice: An Anthology, ed. Hugh LaFollette, 3-10. Hoboken: Wiley-Blackwell, eBook Collection (EBSCOhost), EBSCOhost (accessed September 1, 2016).

Lapsley, D. K. and Narvaez, D. 2006. Character Education in Handbook of Child Psychology, 6th ed, volume four: Child Psychology in Practice, volume ed. K. A. Renninger and I. E. Sigel, 248-296. Hoboken: Wiley.

Lau, C.L.L. 2010. A step forward: ethics education matters! Journal of Business Ethics 92(4): 565-584.

Morality, Cambridge Dictionary, accessed September 1, 2016, http://dictionary.cambridge. org/dictionary/english/morality.

Narvaez, D. 2006. Integrative Ethical Education. In Handbook of Moral Development, ed. M. Killen and J.G. Smetana, 703-72. Mahwah: Lawrence Erlbaum Associates Publishers.

Park, M. 2012. The relationship of ethics education to moral sensitivity and moral reasoning skills of nursing students. Nursing Ethics 19(4): 568-580.

Peters, R.S. 2010. What is an educational process? In The Concept of Education, ed. R.S. Peters, 1-16. New York: Taylor \& Francis e-Library.

Rachels, J. 2003. The Elements of Moral Philosophy, 4th edition. New York: McGraw-Hill.

Rich, K.L. 2016. Introduction to Ethics. In Nursing Ethics: Across the Curriculum and into Practice, 4th edition, ed. J.B. Butts and K.L. Rich, 3-30. Burlington: Jones \& Bartlett Learning.

Robichaux, C. 2012. Developing ethical skills: from sensitivity to action. Critical Care Nurse 32(2): 65-72.

Sanders, S., and K. Hoffman. 2010. Ethics education in social work: comparing outcomes of graduate social work students. Journal of Social Work Education 46(1): 7-22.

Schowengerdt, C. G. 2014. Ethics. Zanesville: Y-City Publishing LLC, eBook \& Streaming Video Collection (Gumberg Library), EBSCOhost (accessed September 5, 2016).

Schwitzgebel, E., et al. 2012. Ethicists' courtesy at philosophy conferences. Philosophical Psychology 25(3): 331340 .

Tawil, S. Cougoureux, M. 2013. Revisiting learning: the treasure within assessing the influence of the 1996 Delors report. UNESCO Education Research and Foresight Occasional Papers.

Ten Have, H. 2008. Unesco's ethics education programme. Journal of Medical Ethics 34(1): 57-59.

Ten Have, H.A.M.J. 2014. Bioethics Education. In Handbook of Global Bioethics, ed. H.A.M.J. ten Have and B. Gordijn, 447-466. Dordrecht: Springer Science+Business Media.

Ten Have, H. 2016. Global Bioethics An Introduction. London: Routledge Taylor \& Francis Group.

The Rise of Results-Based Financing in Education 2015, World Bank Group, accessed September 5, 2016, http:/www.worldbank.org/content/dam/Worldbank/Brief/Education/RBF_ResultsBasedFinancing_v9_ web.pdf.

Thornton, B.C., D. Callahan, and J.L. Nelson. 1993. Education expanding the circle of participants. The Hastings Center Report. 23(1): 25-29.

Tikly, L., and A.M. Barrett. 2011. Social justice, capabilities, and the quality of education in low income countries. International Journal of Educational Development 31: 3-14.

UNESCO Education Strategy 2014-2021, UNESCO, accessed September 7, 2016, http://unesdoc.unesco. org/images/0023/002312/231288e.pdf

Universal Declaration on Bioethics and Human Rights. 2009. In UNESCO Universal Declaration on Bioethics and Human Rights: Background, Principles and Application, ed. H.A.M.J. Ten Have and M.S. Jean, 360-365. Paris: UNESCO Publishing.

Weber, M. 2004. trans. Rodney Livingstone. In The Vocation Lectures Science as a Vocation Politics as a Vocation, ed. D. Owen and T.B. Strong. Indianapolis: Hackett Publishing Company.

World Bank Group. 2011. Learning for All Investing in People's Knowledge and Skills to Promote Development Learning. Washington: The World Bank.

Wright, M. 1995. Can moral judgement and ethical behaviour be learned? Management Decision 33(10): 17-28. 